\title{
A near infrared light-triggerable modular formulation for the delivery of small biomolecules
}

Vitor Francisco ${ }^{1}$, Miguel Lino ${ }^{2}$ and Lino Ferreira ${ }^{1,2^{*}}$

\begin{abstract}
Background: Externally triggered drug delivery systems hold considerable promise for improving the treatment of many diseases, in particular, diseases where the spatial-temporal release of the drug is critical to maximize their biological effect whilst minimizing undesirable, off-target, side effects.

Results: Herein, we developed a light-triggerable formulation that takes advantage of host-guest chemistry to complex drugs functionalized with a guest molecule and release it after exposure to near infrared (NIR) light due to the disruption of the non-covalent host-guest interactions. The system is composed by a gold nanorod (AuNR), which generates plasmonic heat after exposure to NIR, a thin layer of hyaluronic acid immobilized to the AuNR upon functionalization with a macrocycle, cucurbit[6]uril (CB[6]), and a drug functionalized with a guest molecule that interacts with the macrocycle. For proof of concept, we have used this formulation for the intracellular release of a derivative of retinoic acid (RA), a molecule known to play a key role in tissue development and homeostasis as well as during cancer treatment. We showed that the formulation was able to conjugate approximately $65 \mu \mathrm{g}$ of RA derivative per mg of CB[6] @AuNR and released it within a few minutes after exposure to a NIR laser. Importantly, the bioactivity of RA released from the formulation was demonstrated in a reporter cell line expressing luciferase under the control of the RA receptor.
\end{abstract}

Conclusions: This NIR light-triggered supramolecular-based modular platform holds great promise for theranostic applications.

Keywords: Modular platform, NIR light trigger, Gold nanorods, Host-guest chemistry, Temperature control

\section{Introduction}

Intracellular delivery of biomolecules is quintessential for the modulation of cellular processes, cellular reprogramming and gene editing [1,2]. Many of these molecules act at the intracellular level and thus require transporters to cross the cell membrane. Several nanocarriers have been developed to facilitate the intracellular transport of biomolecules [3-5]. For example, liposomes and polymer technologies have been frequently used as drug delivery systems [6, 7]. More recently, light-triggerable nanocarriers have been proposed as an alternative to other type

\footnotetext{
*Correspondence: Lino@uc-biotech.pt

${ }^{1}$ CNC-Center for Neurosciences and Cell Biology, University of Coimbra, 3004-517 Coimbra, Portugal

Full list of author information is available at the end of the article
}

of synthetic carriers given their potential to release the biomolecule of interest in a spatial-temporal controlled manner thus maximizing the therapeutic effect whilst reducing the negative side-effects [8-10]. Indeed, we have recently developed several light-triggerable nanocarriers that had the capacity to orchestrate the intracellular delivery of proteins [11], miRNAs [9] and small molecules [12]. Despite these advances, the proposed strategies relied on the complex and time-consuming synthesis of photo-cleavable linkers for the attachment of biomolecules with different chemistries.

By taking advantage of noncovalent interaction between host and guest molecules, supramolecular chemistry has been shown to be a promising approach for the controlled release of drugs [13]. Cucurbit[n] urils 
$(\mathrm{CB}[n])$ are a family of macrocycles, with a pumpkinshaped structure composed of $n$ glycoluril units $(n=5-8$, 10,14 ) bridged by methylene groups, which form stable host-guest inclusion complexes with a wide variety of guest molecules $[14,15]$. The remarkable selectivity and affinity of this class of macrocycles is driven by a combination of ion dipole interactions, hydrogen bonds, and hydrophobic effects [16]. Unfortunately, the use of supramolecular chemistry, in particular the one based on $\mathrm{CB}[\mathrm{n}]$, is largely unexplored for the design of light-triggerable drug-releasing systems $[17,18]$.

Here, we report a light-triggerable system that is based on a light-triggerable antenna, formed by a gold nanorod (AuNR), coated with a polymeric coating conjugated with cucurbit [6] uril (CB[6]) (host molecule) (Fig. 1a). This system can be used to immobilize any biomolecule conjugated with guest molecules displaying variable affinity to $\mathrm{CB}[6]$. In contrast to previously reported light-triggerable systems, the current approach relies on a core system that regardless of the chemistry of the biomolecule to be delivered, does not change. The interaction of the biomolecules to the nanocarrier is solely dictated by the chemistry of the guest molecule attached to the biomolecule, making it a simple system for the delivery of multiple biomolecules without requiring extensive chemical modifications. The selection of AuNRs was based on the fact that these nanomaterials (i) have been widely used for drug delivery [19], bioimaging [20] and hyperthermia [21], due to their simple synthesis, facile surface modification, adaptable conjugation with biomolecules and tunable optical properties [19,22] and (ii) they can absorb NIR light, which has higher tissue penetration than UV/blue light radiation, and convert it in photothermal energy [23]. Based on these premises, we hypothesized that the increase in local temperature could reduce the interaction between the host and the guest releasing the later in a controlled manner. For proof of concept, we have used all-trans retinoic acid (RA) modified with guest molecules as a model biomolecule. RA controls the biological activity of neural stem cells [24, 25], leukemia cells [26], and endothelial progenitor cells [27]. In addition, RA is a powerful anti-cancer agent, currently being used in several types of cancers [28-31], such as acute promyelocytic leukemia (APL) [32]. Our results showed that the light-triggerable formulation provided an excellent platform to control the release of RA derivatives and ultimately elicit a local response at the cellular level.

\section{Experimental section} NMR spectrometry

${ }^{1} \mathrm{H}$ NMR spectra were recorded on a Bruker Avance III spectrometer at $400 \mathrm{MHz}$. The spectra were recorded in $\mathrm{D}_{2} \mathrm{O}$ using a pulse of $90^{\circ}$ and relaxation delay of $4.0 \mathrm{~s}$. The residual solvent (non-deuterated) was used as the internal reference.

\section{FTIR analyses}

FTIR spectra were recorded with a Nicolet Magna-IR 550 spectrometer (Madison, WI). The dry samples were powdered, mixed with $\mathrm{KBr}$, and pressed into pellets under reduced pressure. The FTIR spectra were obtained by recording 128 scans between 4000 and $650 \mathrm{~cm}^{-1}$ with a resolution of $2 \mathrm{~cm}^{-1}$.

\section{UV-Vis and fluorescence spectroscopy}

UV-Vis and fluorescence analysis was recorded on a Synergy $\mathrm{H} 1$ microplate reader.

\section{Microcalorimetry}

The microcalorimetric titrations were performed using an isothermal titration microcalorimeter (VP-ITC, Malvern) at atmospheric pressure and at a specific temperature. In each run, a solution of guest in a $0.27 \mathrm{~mL}$ syringe was sequentially injected with stirring at $351 \mathrm{rpm}$ in a solution of host in the sample cell. Each solution was degassed and thermostated by using a ThermoVac accessory before titration. In all experiments the first injection was rejected to eliminate diffusion effects of material from the syringe onto the calorimetric cell. The ITC experiments were analyzed with the software ORIGIN (provided by Malvern Inc.) by using the "one set of binding sites" model to simultaneously compute the binding stoichiometry $(N)$, complex stability constant $\left(K_{\mathrm{a}}\right)$, standard molar reaction enthalpy $\left(\Delta H^{\circ}\right)$ and standard deviation from the titration curve.

\section{Confocal microscopy}

Images were acquired using a Zeiss LSM 710 confocal microscope (Carl Zeiss, Jena, Germany) with a $40 \times$ objective/1.4 numerical aperture oil PlanApochromat immersion lens. Alexa-fluor 488 fluorescence was detected using the $488 \mathrm{~nm}$ laser line of an Ar laser and an LP 505 filter. TRITC fluorescence was detected using a $561 \mathrm{~nm}$ HeNe laser $(1 \mathrm{~mW})$ and an LP 560 filter and Alexa-fluor 633 fluorescence was detected using a $633 \mathrm{~nm}$ HeNe. Z-stacks were acquired to confirm the intracellular localization of TRITC labelled AuNRs. The thickness of the slices and the interval between slices were set to $0.7 \mu \mathrm{m}$. After irradiation, cells were deposited onto a glass slide using cytospin centrifugation $(800 \mathrm{rpm}$, $5 \mathrm{~min}$ ), fixed with 4\% PFA for $20 \mathrm{~min}$ and stained for confocal microscopy. Cell membrane was stained with monoclonal mouse anti-human CD45 antibody, diluted 1:50 (R\&D Systems, MAB1430) and using Alexa Fluor488 goat anti-mouse igG as secondary antibody, diluted 1:1000 (Life technologies, A11001). For staining early 
a

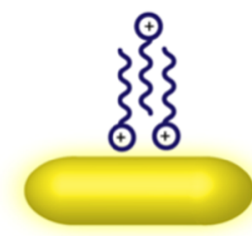

CTAB@AUNR

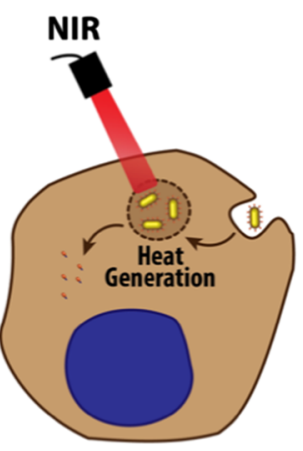

b

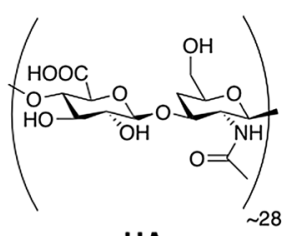

HA
Cellular uptake
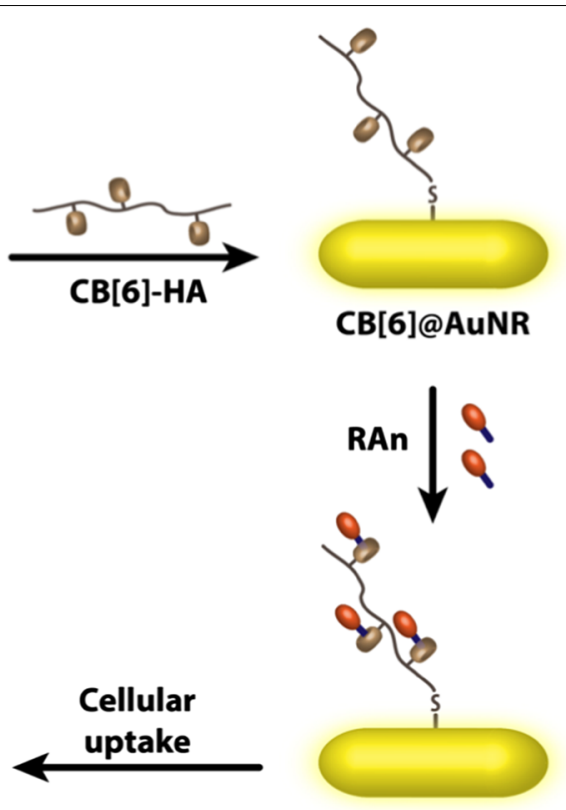

\section{RAn-CB[6]@AuNR}

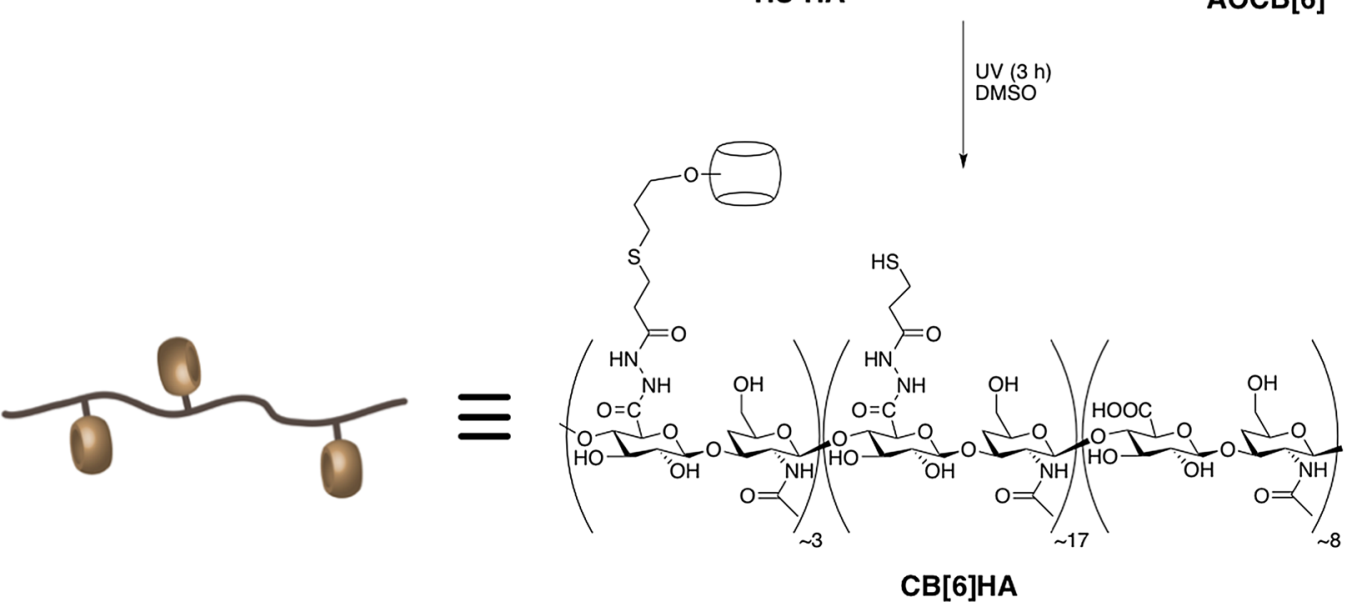

Fig. 1 a Schematic representation of the preparation of RAn-CB[6] @AuNR formulation for the intracellular delivery of RA after NIR activation. $\mathbf{b}$ Scheme for the synthesis of $\mathrm{CB}[6] \mathrm{HA}$ conjugate. HA (8-15 kDa) was reacted with 3,3'-dithiobis(propanoic hydrazine) (DTP) in the presence of 1-ethyl-3-[3-(dimethylamino)propyl]carbodiimide (EDC) and then dithiothreitol (DTT) to obtain 70\% thiolated HA (HS-HA). Next, HS-HA was reacted with (allyloxy) ${ }_{12} \mathrm{CB}[6]$ in DMSO for $3 \mathrm{~h}$ under UV light to obtain CB[6] HA (DS=8 $11 \mathrm{~mol} \%$ ) 
endosomes, cells were permeabilized with $0.1 \%$ TRITON X-100 for $10 \mathrm{~min}$ and stained with rabbit anti-EEA1 monoclonal antibody (Cell Signaling Technology, 3288), diluted 1:100. Alexa Fluor-633 goat anti-rabbit (Life Technologies, A21070), diluted 1:1000 was used as secondary antibody. Cell nuclei were stained with DAPI.

\section{Synthesis of RA conjugates}

The conjugates were prepared using a procedure described elsewhere [33-35]. The synthesis of conjugate RA1 ((2E,4E,6E,8E)-N-(4-(1H-imidazol-1-yl)phenyl)3,7-dimethyl-9-(2,6,6-trimethylcyclohex-1-en-1-yl) nona-2,4,6,8-tetraenamide) was performed as follows: a solution of 4-(1H-Imidazol-1-yl)aniline (IA) $(51.5 \mathrm{mg}$, $0.32 \mathrm{mmol}$, Sigma-Aldrich) and N,N-diisopropylethylamine (DIPEA) $(50 \mu \mathrm{L}, 0.29 \mathrm{mmol}$, Sigma-Aldrich) in $1.0 \mathrm{~mL}$ of dimethylformamide (Alfa Aesar) was added dropwise to an ice-cold suspension of RA (121.5 mg, $0.40 \mathrm{mmol}$, Sigma-Aldrich), 1-hydroxybenzotriazole hydrate (HOBt) (61.2 mg, $0.45 \mathrm{mmol}$, Sigma-Aldrich), $N, N, N^{\prime}, N^{\prime}$-tetramethyl-O- $(1 \mathrm{H}$-benzotriazol-1-yl) uronium hexafluorophosphate (HBTU) (171.8 mg, $0.45 \mathrm{mmol}$, Sigma-Aldrich) and DIPEA (230 $\mu \mathrm{L}$, $1.33 \mathrm{mmol}$ ) in $2.5 \mathrm{~mL}$ of dimethylformamide and the resulting solution was stirred overnight at room temperature. Volatile components were removed under vacuum before column chromatography purification and, upon evaporation of the solvents, pure compound RA1 (93 mg, $65 \%$ ) was obtained, as a yellow solid.

The synthesis of conjugate RA2 ((2E,4E,6E, 8E)$\mathrm{N}$-(6-a minohexyl)-3,7-dimethyl-9-(2,6,6-trimethylcyclohex-1-en-1-yl)nona-2,4,6,8-tetraenamide) and RA3 ((2E,4E,6E,8E)-N-(3-((4-((3-aminopropyl)amino) butyl)amino)propyl)-3,7-dimethyl-9-(2,6,6-trimethylcyclohex-1-en-1-yl)nona-2,4,6,8-tetraenamide) was performed as follows: to an ice-cold solution of RA (100 mg, $0.33 \mathrm{mmol})$ in dry tetrahydrofuran (THF) $(1 \mathrm{~mL}$, SigmaAldrich) was added sequentially $\mathrm{N}$-hydroxysuccinimide (NHS) $\left(57.5 \mathrm{mg}, 0.5 \mathrm{mmol}\right.$, Sigma-Aldrich) and $N, N^{\prime}-$ dicyclohexylcarbodiimide (DCC) $(82.5 \mathrm{mg}, 0.4 \mathrm{mmol}$, Sigma-Aldrich) and the resulting mixture was stirred overnight at room temperature. The precipitated dicyclohexylurea was filtered off (WLP filter funnel, porosity 4) and washed several times with EtOAc (Fisher Chemical). The combined filtrates were washed sequentially with ice-cold $5 \%$ aqueous (aq.) solution of sodium bicarbonate (Sigma-Aldrich), water and once with brine. The organic layer was dried over $\mathrm{Na}_{2} \mathrm{SO}_{4}$ (Panreac), followed by filtration and evaporation of the solvent in a rotary evaporator ( $\mathrm{T}_{\text {water bath }}=45^{\circ} \mathrm{C}$, Vacuubrand PC 500 series) left a yellow solid, succinimidyl all-trans-retinoate. Next, to an ice-cold solution of 1,6-hexanediamine (HMA) (0.05 g, $0.43 \mathrm{mmol}$, Sigma-Aldrich) or spermine (0.1 g,
$0.5 \mathrm{mmol}$, Sigma-Aldrich) in dichloromethane (DCM) (5 mL, Fisher Chemical) a solution of succinimidyl alltrans-retinoate $(0.05 \mathrm{~g}, 0.125 \mathrm{mmol})$ in DCM $(5 \mathrm{~mL})$ was added dropwise during $30 \mathrm{~min}$ and the resulting mixture was stirred overnight at room temperature. The reaction mixture was diluted with dichloromethane and washed sequentially with an ice-cold $5 \%$ aqueous solution of sodium bicarbonate and brine. Next, the mixture was dried overnight with $\mathrm{Na}_{2} \mathrm{SO}_{4}$, followed by filtration, evaporation of the solvent and purified by HPLC to obtain pure products RA2 (0.22 g, 46\%) and RA3 (0.24 g, 40\%).

\section{Compounds purification}

Compound RA1 was purified by column chromatography packed with silica gel 60A $(60-200 \mu \mathrm{m}$, Acros) and the purification process monitored by thin layer chromatography (TLC) on aluminium plates coated with $60 \mathrm{~F}_{254}$ $(0.2 \mathrm{~mm}$, Merck). Spots were visualized with UV light at $254 \mathrm{~nm}$ or ninhydrin (Sigma-Aldrich). The eluent system used was hexane/ethyl acetate $(6: 4, \mathrm{v} / \mathrm{v})$. Analytical RP-HPLC was performed on a Shimazo Prominence-I LC-2030 C 3D and elution of the compounds was monitored by absorbance at $254 \mathrm{~nm}$. Compound purity was assessed using a XBridge C18 $3.5 \mu \mathrm{m} 4.6 \times 250 \mathrm{~mm}$ column (Waters) and a linear gradient of $10-60 \%$ acetonitrile (containing $0.08 \%$ TFA) in water (containing $0.08 \%$ TFA) for compounds RA2 and RA3 over $40 \mathrm{~min}$ at a flow rate of $1 \mathrm{~mL} / \mathrm{min}$.

\section{Synthesis and characterization of thiolated hyaluronic acid} (HA)

The synthesis of thiolated HA (HS-HA) was prepared as described elsewhere [36]. Briefly, HA sodium salt (0.2 g, $0.5 \mathrm{mmol}, \mathrm{Mw}=8-15 \mathrm{kDa}$, Carbosynth Limited, Berkshire, UK) was dissolved in $20 \mathrm{~mL}$ of water followed by the addition of 3,3'-dithiobis(propanoic hydrazide) (DTP) $(0,238 \mathrm{~g}, 1.0 \mathrm{mmol}$, Frontier Scientific) while stirring. The $\mathrm{pH}$ of the mixture was adjusted to 4.75 with $\mathrm{HCl}$ (Merck). Next, 1-ethyl-3-[3-(dimethylamino)propyl]carbodiimide (EDC) (0.192 g, $1.0 \mathrm{mmol}$, Sigma-Aldrich) was added in solid form and the mixture stirred for $2.5 \mathrm{~h}$. The reaction was stopped by increasing the $\mathrm{pH}$ to 7.0 with $\mathrm{NaOH}$ (Merck). Then, dithiothreitol (DTT) $(1.0 \mathrm{~g}, 6.5 \mathrm{mmol}$, Acros) was added, the $\mathrm{pH}$ increased to 8.5 , and the mixture was stirred $(250 \mathrm{rpm})$ overnight. After decreasing the $\mathrm{pH}$ of the mixture to 3.5 with $\mathrm{HCl}$, the reaction product was purified by dialysis ( $\mathrm{Mw}$ cutoff $=2 \mathrm{kDa}$ ) against diluted $\mathrm{HCl}, \mathrm{pH}=3.5$, and lyophilized for $48 \mathrm{~h}$ to yield HS-HA. The degree of substitution in HS-HA was determined by ${ }^{1} \mathrm{H}$ NMR (ratio between methylenes of DTP and $\mathrm{N}$-acetyl methyl protons of $\mathrm{HA}$ ) and by free thiol content as measured by an Ellman's test. 


\section{Synthesis of $\mathrm{CB}[6] \mathrm{HA}$ conjugate}

HS-HA with a thiol content of 70\% (5 mg, $10.9 \mu \mathrm{mol})$ was added to a solution of tris(2-carboxyethyl)phosphine hydrochloride (TCEP) (9 mg, $31.8 \mu \mathrm{mol}$, Sigma-Aldrich) in anhydrous DMSO $(2 \mathrm{~mL})$ in a quartz cuvette. Perallyloxycucurbit [6] uril potassium sulfate (AOCB[6]) (10 mg, $5.5 \mu \mathrm{mol}$, Strem Chemicals) was added to the mixture and then irradiated with UV light $(365 \mathrm{~nm}$, $100 \mathrm{~W})$ for $6 \mathrm{~h}$. The unreacted AOCB[6] and TCEP were removed by dialysis for $48 \mathrm{~h}$ (MWCO $12-14 \mathrm{kDa}$ ) against DMSO and water successively. The degree of $\mathrm{CB}[6]$ modification in the HA was assessed by ${ }^{1} \mathrm{H}$ NMR through the ratio between the peaks corresponding to allyloxy groups of AOCB[6] (5.25-6.15 ppm) and $N$-acetyl methyl protons of HA (2.0 ppm).

\section{Preparation of AuNRs}

AuNRs were prepared following the seed-mediated method [37]. The seed solution was prepared by the addition of ice-cold sodium borohydride $\left(\mathrm{NaBH}_{4}\right)(10 \mathrm{mM}$, $0.3 \mathrm{~mL}$, Sigma-Aldrich) to a solution of hexadecyltrimethylammonium bromide (CTAB) $(0.1 \mathrm{M}, 5 \mathrm{~mL}$, Sigma-Aldrich) containing chloroauric acid $\left(\mathrm{HAuCl}_{4}\right.$. aq) $(0.25 \mathrm{mM}$, Sigma-Aldrich). The solution was stirred for $2 \mathrm{~min}$ and then kept at $25{ }^{\circ} \mathrm{C}$ for $8 \mathrm{~min}$. The growth solution was prepared by the sequential addition of silver nitrate $\left(\mathrm{AgNO}_{3}\right)(5 \mathrm{mM}, 3.2 \mathrm{~mL}), \mathrm{HAuCl}_{4} \cdot \times \mathrm{H}_{2} \mathrm{O}$ $(50 \mathrm{mM}, 2 \mathrm{~mL})$ and ascorbic acid $(0.1 \mathrm{M}, 1.5 \mathrm{~mL}$, SigmaAldrich) to a CTAB solution $(0.1 \mathrm{M}, 200 \mathrm{~mL}$, SigmaAldrich), mixing gently after each step. Finally, the seed solution was kept at $28{ }^{\circ} \mathrm{C}$ for $2 \mathrm{~h}$ and then centrifuged twice at $9000 \mathrm{~g}(20 \mathrm{~min})$ to purify the AuNRs.

\section{Characterization of the AuNRs}

AuNRs size were measured with a PHILIPS CM-12 transmission electron microscope at $100 \mathrm{kV}$. A drop of dispersed AuNRs (lyophilized powder) into water was spread on a 200-mesh copper grid coated with a Formvar film, and the extra droplet was instantly wiped off by filter paper. The dried grid was then examined under an electron microscope. Additionally, AuNRs were analysed by photon correlation spectroscopy (PCS) using quasi-elastic light scattering equipment (Zeta-Pals ${ }^{\mathrm{TM}}$ Zeta Potential Analyzer, Brookhaven Instruments Corp., Holtsville, NY) and ZetaPlus ${ }^{\mathrm{TM}}$ Particle Sizing Software (version 4.03). A AuNR suspension before and after functionalization ( $2 \mathrm{~mL}, 50 \mu \mathrm{g} / \mathrm{mL}$ in water of molecular biology) was added to a cuvette and allowed to stabilize for $10 \mathrm{~min}$ and then analysed (3 times) at room temperature. In some experiments, the cuvette was then exposed to NIR light $\left(780 \mathrm{~nm}, 2 \mathrm{~W} / \mathrm{cm}^{2}\right)$ for $3 \mathrm{~min}$ and the values of $\mathrm{NP}$ diameter and NP counts (Kcps) were recorded. The zeta potential of NPs was determined in a $1 \mathrm{mM} \mathrm{KCl}$, at $25^{\circ} \mathrm{C}$
$(2 \mathrm{~mL}, 50 \mu \mathrm{g} / \mathrm{mL})$. All data were recorded with at least 5 runs (in triplicate) with a relative residual value (measure of data fit quality) of 0.03 . Nanoparticles tracking analysis (NTA) measurements were performed using the NS300 Particle Measuring Instrument from NanoSight Ltd (NanoSight, GB) containing a sample chamber of $0.25 \mathrm{~mL}$, a $532 \mathrm{~nm}$ laser and a camera sCMOS. For each run, about $1 \mathrm{~mL}$ of the sample was manually injected into the chamber at $37^{\circ} \mathrm{C}$. Five videos of $30 \mathrm{~s}$ duration were taken, with a frame rate of 30 frames per second. For data capturing and data evaluation, the NTA 3.2 analytical software was used (NanoSight Ltd). In the analysis, the mode size (main peak), mean size and its standard deviation values were obtained.

\section{Temperature profile of AuNR suspensions}

The temperature variation upon irradiation a suspension of RAn-CB[6] @AuNR (10 or $50 \mu \mathrm{g} / \mathrm{mL}$ in RPMI medium) was recorded using an infrared camera (FLIR SC5650). The AuNR suspension in a 24 well plate was irradiated with a continuous wave NIR laser $(780 \mathrm{~nm})$ at a power density of $2 \mathrm{~W} / \mathrm{cm}^{2}$. The volume used for each well was fixed at $0.4 \mathrm{~mL}$ and RPMI medium was used as a control. The laser beam was collimated and expanded to a circular Gaussian beam with a diameter of about $9 \mathrm{~mm}$.

\section{Preparation of $\mathrm{CB}[6]$ @AuNR complex}

Functionalization of CTAB@AuNR was performed through ligand exchange with $\mathrm{CB}[6] \mathrm{HA}$ in water. $\mathrm{CB}[6]$ HA solution $(500 \mu \mathrm{L}, 2 \mathrm{mg} / \mathrm{mL})$ was added to the AuNR suspension $(2 \mathrm{~mL}, 0.3 \mathrm{nM})$, stirred for $4 \mathrm{~h}$, and $\mathrm{CB}[6]$ $@$ AuNR was purified by centrifugation at $10,000 \mathrm{~g}$ for 25 min twice and finally dispersed in cell culture RPMI1640 medium ((Gibco) supplemented with $10 \%$ fetal bovine serum (Gibco) and $100 \mathrm{U} / \mathrm{mL}$ PenStrep (Lonza). The average number of $\mathrm{CB}[6]$ HA molecules bound to a single AuNR was calculated indirectly, i.e. by the quantification of $\mathrm{CB}[6] \mathrm{HA}$ not bounded to AuNRs (in the supernatant after centrifugation) using a colorimetric assay with anthrone/sulfuric acid [38].

\section{Drug loading in AuNRs}

The RA conjugates concentration in the supernatant was determined by a UV-vis spectrophotometer at $350 \mathrm{~nm}$ to calculate the drug loading content. The drug loading content and entrapment efficiency were calculated by the following equations: Loading content $=$ (weight of drug in $\mathrm{CB}[6] @ A u N R) /($ weight of $\mathrm{CB}[6] @ A u N R) ;$ Entrapment efficiency $=($ weight of drug in $\mathrm{CB}[6] @ A u N R) /($ initial weight of drug). In the in vitro drug release experiment, a suspension of RAn-CB6@AuNR $(1 \mathrm{~mL}, 10 \mu \mathrm{g} / \mathrm{mL})$ was agitated at $37{ }^{\circ} \mathrm{C}$ followed by centrifugation at $10,000 \mathrm{~g}$ during $25 \mathrm{~min}$ at $37^{\circ} \mathrm{C}$. The supernatant was collected 
and the amount of released drug was determined by measuring the absorption at $350 \mathrm{~nm}$ using a UV-vis spectrometer and calculated by the linear regression equation $\mathrm{y}=0.1018 \times\left(R^{2}=0.99\right)$ for RA1, $\mathrm{y}=0.102 \times\left(R^{2}=0.99\right)$ for RA2 and $\mathrm{y}=0.0995 \times\left(R^{2}=0.99\right)$ for RA3.

\section{Cell Culture}

Human bone marrow acute promyelocytic leukemia NB4 cells, kindly provided by Dr. Arthur Zelent (Institute of Cancer Research, Royal Cancer Hospital), were cultured in supplemented RPMI-1640 medium (Gibco) $[10 \%$ fetal bovine serum (Gibco) and $100 \mathrm{U} / \mathrm{mL}$ PenStrep (Lonza)] in a $\mathrm{CO}_{2}$ incubator at $37^{\circ} \mathrm{C}, 5 \% \mathrm{CO}_{2}$ in a humidified atmosphere. NB4-RARE cell line generation was obtained as previously reported by us [26]. Cells were passaged every 2-3 days and used for experiments between passage 2 and 8 .

\section{Release studies of RA from RAn-CB[6] @AuNRs}

The release of RA from RAn-CB[6] @AuNRs was evaluated by a biological assay, using a reporter cell line (NB4RARE cells) that expresses luciferase after the activation of the RA receptor [26]. Prior to cell transfection, a RAnCB[6] @AuNR suspension (50 $\mu \mathrm{g} / \mathrm{mL})$ in RPMI medium was irradiated outside the cells with NIR light for $2 \mathrm{~min}$ $\left(780 \mathrm{~nm}, 2 \mathrm{~W} / \mathrm{cm}^{2}\right)$, centrifuged $\left(25 \mathrm{~min}, 10,000 g, 37^{\circ} \mathrm{C}\right)$, collected the supernatant $(1 \mathrm{~mL})$ and resuspended the pellet in fresh medium. NB4-RARE cells $\left(2.0 \times 10^{4}\right.$ cells/ well) were plated in V-shaped 96-well plates and immediately cultured with RA1 $(1 \mu \mathrm{M})$, RA2 $(1 \mu \mathrm{M})$, supernatant of RA1 and RA2 and resuspended pellet $(50 \mu \mathrm{g} / \mathrm{mL})$ for $4 \mathrm{~h}$ in supplemented RPMI-1640 medium. The cells were then washed with PBS and centrifuged $(250 g, 5 \mathrm{~min})$ to remove non-internalized AuNRs. Following transfection, cells were cultured for $20 \mathrm{~h}$ in supplemented RPMI-1640 medium. After this time, cells were centrifuged and then resuspended in cell lysis buffer $(60 \mu \mathrm{L}$; the buffer was composed by $2.5 \mathrm{mM}$ of magnesium chloride, $33 \mathrm{mM}$ DL-dithiothreitol, $0.1 \mathrm{mM}$ ethylenediaminetetraacetic acid, $20 \mathrm{mM}$ tricine, $2.5 \mathrm{mM}$ magnesium sulfate and $1 \%$ Triton X-100). To allow complete lysis of the cells, the plate was kept on ice under agitation for $15 \mathrm{~min}$ and subsequently stored at $-80^{\circ} \mathrm{C}$ for the amount of time necessary to freeze the samples. Finally, the plate was thawed at slow rate on ice and the luciferase luminescence was quantified, in a well-by-well mode, in a microplate luminometer reader LumiStar Galaxy (BMG Labtech), at $37^{\circ} \mathrm{C}$ with constant agitation, by adding, with an injector, the reading buffer $(100 \mu \mathrm{L}$; the reading buffer was formed by $0.5 \mathrm{mM}$ luciferin, $0.5 \mathrm{mM}$ ATP, $2.5 \mathrm{mM}$ of magnesium chloride, $33 \mathrm{mM}$ DL-dithiothreitol, $0.1 \mathrm{mM}$ ethylenediaminetetraacetic acid, $20 \mathrm{mM}$ tricine and $2.5 \mathrm{mM}$ magnesium sulfate) to the sample $(50 \mu \mathrm{L})$. Protein was quantified using Pierce BCA Protein Assay Kit (Thermo Scientific) in order to normalize the luminescence signal to the mass of protein in each condition. All measures were performed in triplicate.

\section{CB[6] @AuNR internalization studies}

The amount of RAn-CB[6] @AuNR internalized by NB4 cells was monitored by inductively coupled plasma mass spectroscopy (ICP-MS). The intracellular levels of $\mathrm{Au}$ were measured before and after cell exposure. NB4 cells $\left(20 \times 10^{3} \mathrm{cell} /\right.$ well $)$ were plated in 96 well plates and incubated with RPMI-1640 medium from 1 to $24 \mathrm{~h}$ with RAnCB[6] @AuNRs $(50 \mu \mathrm{g} / \mathrm{mL})$. After incubations, the cells were centrifuged and washed with PBS (three times), followed by the addition of an aqueous solution of nitric acid $[1 \mathrm{~mL}, 69 \%(\mathrm{v} / \mathrm{v})]$. The intracellular concentration of $\mathrm{Au}$ was quantified by ICP-MS and normalized per cell. The estimation of AuNRs was done based on controlled standard solutions.

\section{Cytotoxicity of CB[6] @AuNR}

To assess the cytotoxicity of AuNRs, NB4 cells were incubated for $4 \mathrm{~h}$ in a 96 well plate $\left(20 \times 10^{3}\right.$ cell/well $)$ with variable amount of RAn-CB[6] @AuNRs (concentration between 10 and $100 \mu \mathrm{g} / \mathrm{mL}$ ). After incubation, cells were washed twice with PBS by centrifugation $(300 g-5 \mathrm{~min})$ to remove non-internalized AuNRs. Then, cells were left in the incubator with RPMI medium for additional $20 \mathrm{~h}$ and the ATP production was measured by a Celltiter-Glo Luminescent Cell Viability Assay (Promega, USA) performed according to the manufacturer's instructions.

\section{Labelling of CB[6] @AuNR with TRITC}

Thiol-PEG-amine $5 \mathrm{kDa}$ (100 nmol, Creative PEGworks) was reacted with tetramethylrhodamine isothiocyanate (TRITC) (200 nmol, Sigma-Aldrich) in $1 \mathrm{~mL}$ of $100 \mathrm{mM}$ carbonate buffer at $\mathrm{pH} 9.2$ for $2 \mathrm{~h}$ at room temperature. Then CB[6] @AuNR (500 $\mu \mathrm{L}, 0.2 \mathrm{nM})$ were incubated overnight with thiol-PEG-TRITC in a molar ratio of 1:1000. The excess fluorophore was removed in two steps of centrifugation at $10,000 \mathrm{~g}$ for $25 \mathrm{~min}$.

\section{NB4 differentiation assay}

Myelocytic differentiation of NB4 cells was assessed by quantifying $\mathrm{CD}_{11} \mathrm{~b}^{+}$population using flow cytometry. NB4 cells (5000 cells/condition) were plated in a 96-well plate and cultured for $4 \mathrm{~h}$ with RAn-CB[6] @AuNR. The cells were then washed by centrifugation $(300 g-5 \mathrm{~min})$ to remove non-internalized AuNRs and irradiated or not with NIR light. After 3 days, NB4 cells were stained with CD11b (clone ICRF44-PE mouse anti-human antibody from BD Pharmingen) for $10 \mathrm{~min}$ at room temperature in the dark. Following incubation, the cells were washed 
twice with $1 \mathrm{~mL}$ of PBS $1 \mathrm{X}$ and centrifuged for $5 \mathrm{~min}$ at $300 \mathrm{~g}$. Then, the cells were suspended in $100 \mu \mathrm{L}$ of PBS $1 \mathrm{X}$ and characterized by a BD Accuri C6 flow cytometer (5000 events were recorded). Unstained cells were used to set the cutoff for the expression of the different markers.

\section{Statistical analysis}

All the experiments were performed at least 3 times. Where applicable, the significance of variability between the results from each group and the corresponding control was determined by unpaired $t$ test or ANOVA. All the results are expressed as means \pm SEM from at least 3 independent experiments.

\section{Results and discussion}

\section{Synthesis and characterization of $\mathrm{CB}[6]$ @AuNRs}

HA was selected for the immobilization of the macrocycle $\mathrm{CB}[6]$ because of its: long biomedical history [39], non-immunogenicity and biodegradability [40], many hydroxyl groups for chemical modification, and recognition by the CD44 receptor expressed by some cells, in particular cancer cells [40]. The synthesis of the CB[6] HA conjugate was obtained by the photoreaction of thiol-functionalized lower molecular weight $\mathrm{HA}$ with the (allyoxy) ${ }_{12} \mathrm{CB}[6]$ as shown in Fig. 1b [41]. The degree of $\mathrm{CB}[6]$ substitution (DS) in the polymer was determined by ${ }^{1} \mathrm{H}$ NMR (Additional file 1: Figure $\mathrm{S} 1$ ) and the results showed a DS of $8 \pm 1 \mathrm{~mol} \%$ of $\mathrm{CB}[6]$ in $\mathrm{HA}$, as calculated by the integration of the polymer acetoamido signal and the $\mathrm{CB}[6]$ signals between 5.25 and $6.0 \mathrm{ppm}$.

The AuNRs were synthesized through a seed-mediated method with CTAB as a stabilizer. The AuNRs had an average length of $40.2 \pm 0.4 \mathrm{~nm}$ and width of $10.3 \pm 0.2 \mathrm{~nm}$, an aspect ratio of $3.9 \pm 0.1$ and showed a plasmon resonance band at $780 \mathrm{~nm}$ (Fig. 2a, d). The removal of $C T A B$ from the longitudinal facet of the rod is challenging and thus the coverage of AuNRs with $\mathrm{CB}[n]$ is not trivial [42, 43]. Previous studies have used a surfactant-free wet chemistry with the subsequent formation of gold nanostars instead of well-defined nanorods $[13,43]$. However, the synthesis of gold nanostars with $\mathrm{CB}[n]$ leads to a decrease in the binding strength of the host-guest complex, since one of the macrocycle portals (able to stabilize guest molecules) is attached to the gold nanostar surface $[13,43]$. Therefore, in the current study, we conjugated the macrocycle to a thiol-modified HA followed by the conjugation of the polymeric derivative to the surface of AuNR. One-pot ligand exchange was the most straightforward approach, and therefore $\mathrm{CB}[6] \mathrm{HA}$ was added directly to an aqueous suspension of CTAB@ AuNRs. To investigate the amount of $\mathrm{CB}[6] \mathrm{HA}$ polymer required for conjugation, we conducted the reaction with different ratios of polymer to AuNRs, ranging from 500 to 50.000, while the concentration of AuNRs was maintained constant (Additional file 1: Figure S2A). Whereas ratios CB[6] HA:AuNRs of 500:1 and 10,000:1 resulted in incomplete exchange and concentration losses due to aggregation of the nanorods (Fig. 2c), stable AuNRs where obtained by using a ratio 50.000:1. To quantitatively evaluate the amount of $\mathrm{CB}$ [6] HA polymer chains in the surface of each AuNR, we used the anthrone assay (Fig. 2c). The results showed the presence of $3252 \pm 354$ polymer chains per AuNR (theoretical ratio 50.000:1), which is in line with results described in the literature for other ligands [44]. To confirm the CTAB replacement by CB[6] HA (from here on denoted as CB[6] @AuNR), the AuNR surface ligand composition was characterized by TEM, UV-Vis, zeta potential, FTIR and chemical analyses.

TEM images of CB[6] @AuNR showed the presence of AuNRs with an aspect ratio of around 3.9, and thus similar to the initial aspect ratio of AuNRs before conjugation with CB[6] HA polymer (Fig. 2b). CB[6] @AuNRs were also characterized by UV-Vis analyses (Fig. 2d) and the same two distinct absorbance peaks were observed at $530 \mathrm{~nm}$ and $780 \mathrm{~nm}$ after ligand exchange, which corresponded to the transverse and longitudinal surface plasmon resonances, respectively. Dynamic light scattering analysis of the AuNRs showed an increase of $17 \pm 3 \mathrm{~nm}$ in length and $8 \pm 2 \mathrm{~nm}$ in width (Additional file 1: Figure S2B, C) [45], while the zeta potential changed from $+31 \pm 3 \mathrm{mV}$ with $\mathrm{CTAB}$ as a ligand to $-25 \pm 2 \mathrm{mV}$ after $\mathrm{CB}[6]$ HA ligand exchange (Fig. 2e). Although zeta potential is the most widely used characterization technique to confirm the surface modification of CTABcapped AuNRs, it does not give information regarding CTAB removal. Therefore, FTIR spectroscopy was used to confirm the ligand exchange process. The FTIR spectra showed the disappearance of the absorptions at 2913 and $2845 \mathrm{~cm}^{-1}$ caused by the $\mathrm{C}-\mathrm{H}$ stretching vibration of methyl and methylene groups of CTAB, confirming the removal of CTAB from AuNR surface (Additional file 1: Figure S2D). Conversely, the bands at 1740 and $1435 \mathrm{~cm}^{-1}$ attributed to $\mathrm{C}=\mathrm{O}$ and $\mathrm{C}-\mathrm{N}$ vibration, respectively, confirmed the immobilization of $\mathrm{CB}[6] \mathrm{HA}$ in the surface of AuNR. Finally, the stability of $\mathrm{CB}[6] @$ AuNRs was studied in cell culture RPMI medium for 3 days (Additional file 1: Figure S2E). Our results showed that the colloidal suspension had an increase of $30 \pm 2 \%$ in size with time, however, the number of nanoparticles in suspension remained the same.

Taken together, we have developed a new chemical strategy to coat AuNRs with macrocycles, specifically $\mathrm{CB}[n]$. The strategy comprised two steps: (i) conjugation of thiolated HA with vinyl-modified $\mathrm{CB}[6]$ and (ii) 


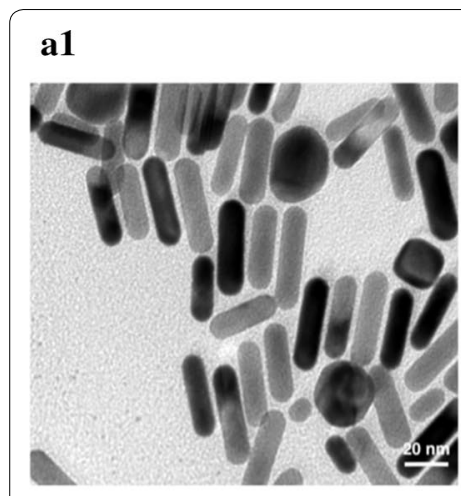

b1
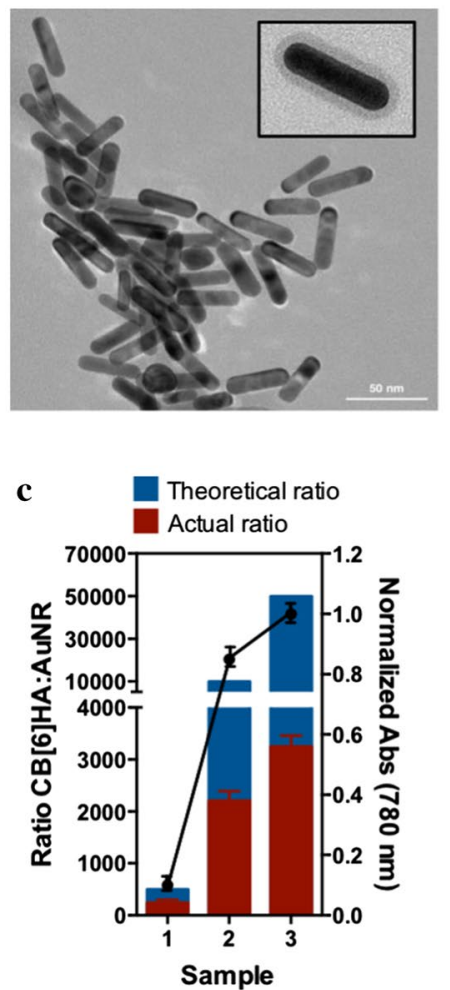

a2

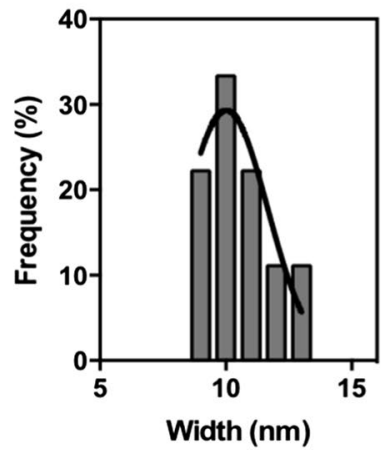

b2

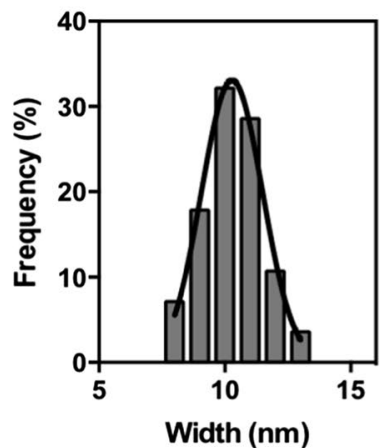

d

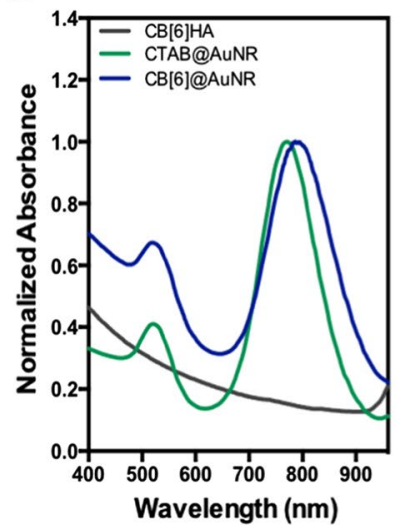

a3

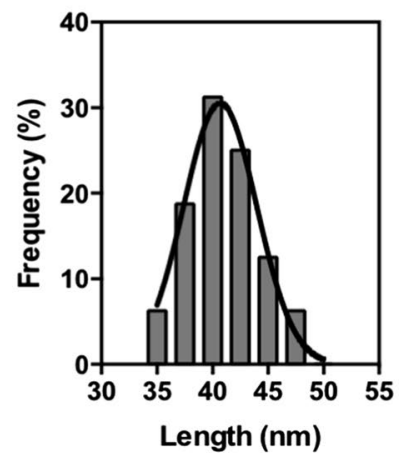

b3

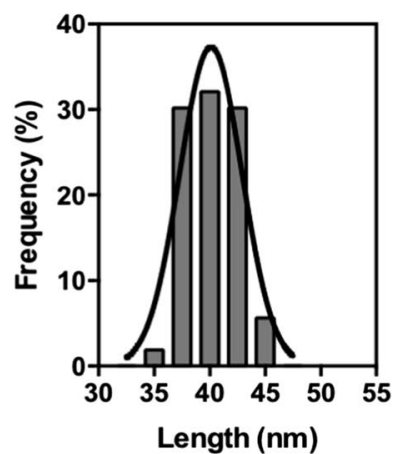

e

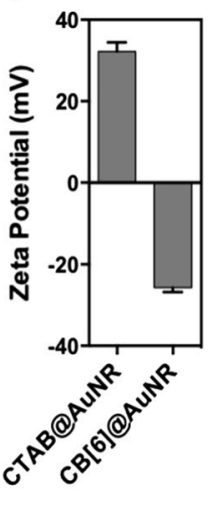

a4

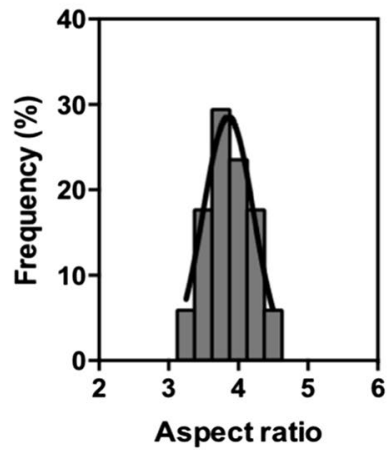

b4

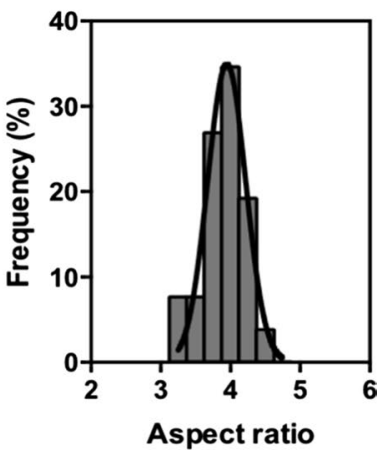

Fig. 2 a Characterization of AuNRs before and after conjugation with CB[6] HA. a, b Representative TEM images of CTAB@AuNR (a.1) and CB[6] @ AuNR (b.1). AuNR width (a.2 and b.2), length (a.3 and b.3) and aspect ratio (a.4 and b.4). The AuNRs showed an average width of $10.3 \pm 0.2 \mathrm{~nm}$, an average length of $40.2 \pm 0.4 \mathrm{~nm}$ and an aspect ratio of $3.9 \pm 0.1$. Results are average \pm SEM $(n=50)$. c Amount of CB[6] HA at the surface of AuNR in different CB[6] HA:AuNR ratios determined by the anthrone assay ( 3252 \pm 354 polymer chain/NR for the theoretical ratio of 50.000:1). Absorbance at $780 \mathrm{~nm}$ was normalised by the absorbance of AuNRs before ligand exchange. Results are average \pm SEM $(n=3)$. Absorbance spectra (d) and zeta potential (e) of AuNRs before (CTAB@AuNR) and after conjugation with CB[6] HA (CB[6] @AuNR)

conjugation of $\mathrm{CB}[6]$ HA to AuNRs by ligand exchange. Although AuNRs coated with HA have been described previously [46], the formulation described here is the first to have a macrocycle for host-guest chemistry.
Light-triggerable release of small molecules from CB[6] @ AuNRs

Next, we evaluated CB[6] @AuNRs as a drug release system (Fig. 3a). For proof of concept, we loaded the 


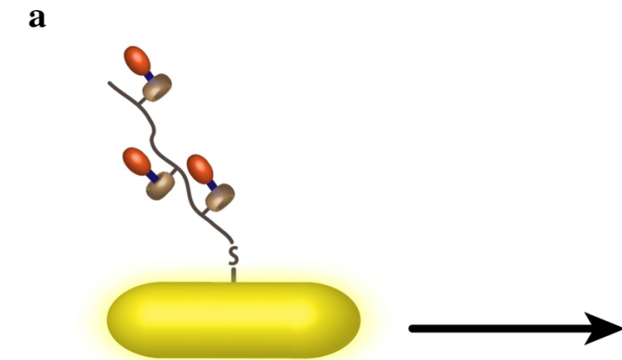

RAn-CB[6]@AuNR

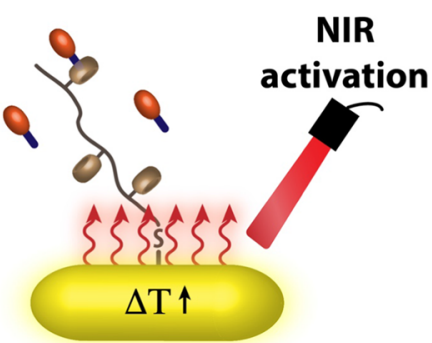

Drug release b

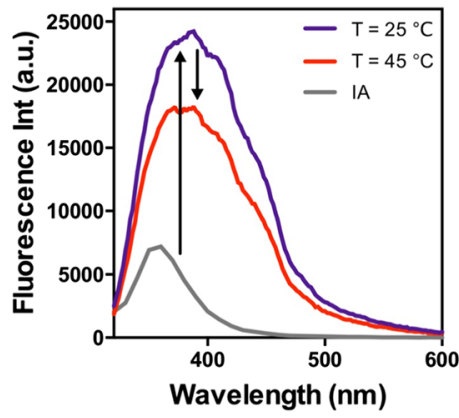

c

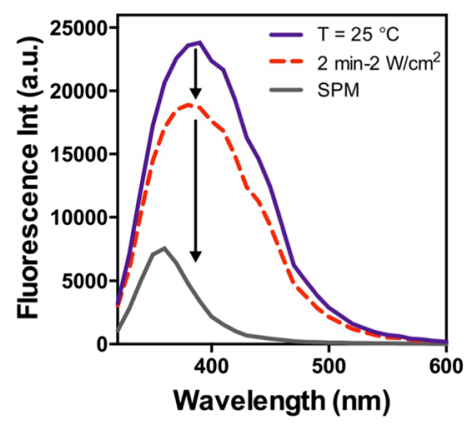

d

RA<smiles>CC(C)CCCC(C)CCC(C)CC1(C)CCCC1C</smiles>

RA1

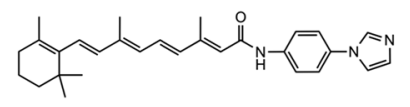

RA2<smiles>CCCCCC(C)CCCC(C)CCC(C)C1(C)CCCC1C</smiles>

RA3 e

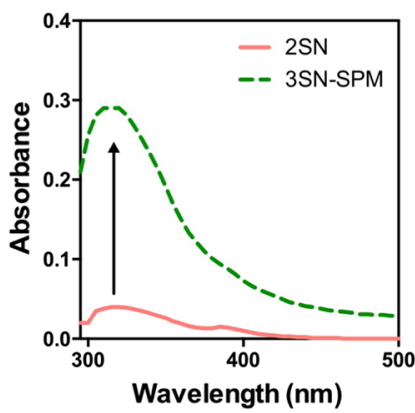

f

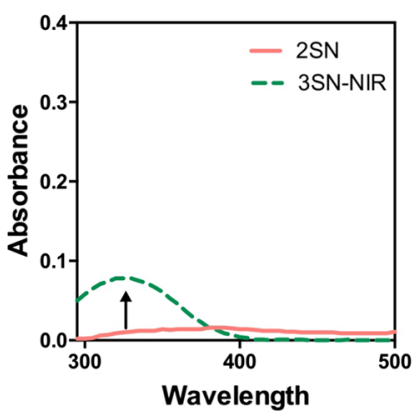

g

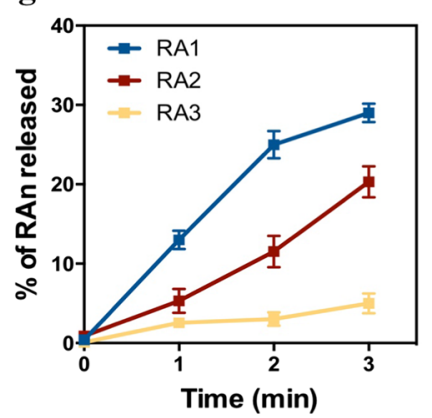

Fig. 3 Release profile of IA and RA from CB[6] @AuNRs. a Schematic representation of the cargo release after irradiation the AuNRs with near-infrared light (780 nm, 2 W/ $\mathrm{cm}^{2}$ ). b Representative fluorescence spectra of IA complexed with CB[6] @AuNR (50 $\left.\mu \mathrm{g} / \mathrm{mL}\right)$ at different temperatures. c Representative fluorescence spectra of IA complexed in CB[6] @AuNR (50 $\mu \mathrm{g} / \mathrm{mL}$ ) upon irradiation with NIR light for 2 min or after adding a competitive ligand (spermine (SPM), $0.5 \mathrm{mM})$ ) to displace IA. d Chemical structures of the RA conjugates. e RA1-CB[6] @AuNRs (10 $\mu \mathrm{g} / \mathrm{mL}$ ) were irradiated by NIR laser, the suspension centrifuged two times (2SN), the supernatant collected and the absorbance measured. At the end, the formulation was suspended in water and a competitive ligand (SPM $0.5 \mathrm{mM}$ ) was added to displace RA1 from AuNRs (3SN-SPM). f Quantification of RA1 released after irradiation with NIR light. After irradiation, the suspension was immediately centrifuged, the supernatant was collected (3SN-NIR) and the amount of RA1 was determined using a calibration curve of RA1.g Percentage of RA1, RA2 and RA3 release upon irradiation the CB[6] @ AuNRs $(10 \mu \mathrm{g} / \mathrm{mL})$ for different times. Results are expressed as average $\pm \operatorname{SEM}(n=3)$

CB[6] @AuNRs with a fluorescent dye, N-(4-aminophenyl)imidazole (IA), with affinity to $\mathrm{CB}[6]$. IA forms a stable 1:1 host-guest complex with $\mathrm{CB}[6]$ $\left(K_{a}=1.0 \times 10^{5} \mathrm{M}^{-1}\right.$ at $\left.25{ }^{\circ} \mathrm{C}\right)$, which upon complexation increases the fluorescence [47]. As expected, the fluorescence of IA increased when IA was added to an aqueous suspension of $\mathrm{CB}[6]$ @AuNRs, indicating the complexation of the guest by the macrocycle (Fig. 3b). When the formulation was heated at $45^{\circ} \mathrm{C}$ the fluorescence of IA decreased due to the displacement of IA from CB[6] (Fig. 3b).

Similar results were obtained when IA-CB[6] @AuNRs suspended in water were exposed to a NIR laser $(780 \mathrm{~nm}$, $2 \mathrm{~W} / \mathrm{cm}^{2}, 2 \mathrm{~min}$ ) (Fig. 3c). The exposure of AuNRs to NIR light causes collective oscillation of surface electrons, which in turn results in a localized heating phenomenon. In agreement with the temperature experiment, the results showed a decrease in the fluorescence intensity 
of IA, indicating the displacement of the dye from the cavity of $\mathrm{CB}$ [6] (Fig. 3c). In both experiments (temperature and NIR activation) the complete displacement was not achieved, at least in the conditions tested, since the addition of a competitive ligand, spermine (SPM; $K_{\text {SPM- }}$ ${ }_{\mathrm{CB}[6]} \approx 10^{12} \mathrm{M}^{-1}$ ), displaced additional ligand from the AuNRs.

Next, we loaded the CB[6] @AuNRs with RA. Since RA was not complexed by the small cavity of $\mathrm{CB}[6]$, three RA conjugate with amines were synthesized (Fig. 3D). The high selectivity and affinity that this type of macrocycles has towards cations through the ion-dipole effect, along with its ability to complex alkyl chains within its hydrophobic cavity, is well known [16]. The three guests conjugated with the RA were selected in order to obtain different binding affinities with $\mathrm{CB}[6]$ (Additional file 1: Figure $\mathrm{S} 3 \mathrm{~A}-\mathrm{C}$ ). The activity of the RA derivatives was evaluated in a reporter cell line that expressed luciferase upon activation of RAR- $\alpha$ receptor by RA. The results showed a similar activity between RA1 and unmodified RA whereas RA2 showed a 50\%-decrease in activity and RA3 a 70\%-decrease as compared to the unmodified RA (Additional file 1: Figure S3D).

The binding affinity for the host-guest complex formation was estimated to be up to $10^{5} \mathrm{M}^{-1}$ for RA1, $10^{6}$ $\mathrm{M}^{-1}$ for RA2 and $10^{12} \mathrm{M}^{-1}$ for RA3 [48]. The amount of loaded RA conjugate was determined by calculating the difference between the amount of RA added to $\mathrm{CB}[6]$ @ AuNRs and the amount of RA determined in the supernatant after centrifugation at $37^{\circ} \mathrm{C}$. In addition, the total amount of RA derivatives complexed in the CB[6] @ AuNRs was also confirmed by adding an excess of a competitive ligand, SPM $(0.5 \mathrm{mM})$ (Fig. 3e). UV-Vis was used to quantify the RA conjugate and the results showed that for the RA conjugate with the smaller binding affinity with $\mathrm{CB}[6]$, RA1, up to $50 \mu \mathrm{g}$ of RA was loaded per $\mathrm{mg}$ of CB[6] @AuNR whereas for RA2 and RA3, the loading was $55 \mu \mathrm{g}$ and $65 \mu \mathrm{g}$, respectively. The amount of RA conjugate released by CB[6] @AuNRs upon irradiation with NIR light was also evaluated. Without irradiation, the absorbance of RA1 in the supernatant was negligible, while after NIR irradiation, there was significant increase of the RA1 absorbance in the supernatant (Fig. 3f). Indeed, thirty percent of RA1 was released after $3 \mathrm{~min}$ exposure to NIR laser with power of $2 \mathrm{~W} / \mathrm{cm}^{2}$ (Fig. $3 \mathrm{~g}$ ) which corresponded to an increase of $10 \pm 1{ }^{\circ} \mathrm{C}$ in the $\mathrm{CB}[6] @ A u N R$ suspension (Additional file 1: Figure S4A). Importantly, the irradiation of the RA1-CB[6] @AuNR suspension for 3 min did not affect the stability of AuNRs in suspension (Additional file 1: Figure S4B). The percentage of RA2 and RA3 released was $20 \%$ and $7 \%$, respectively, due to higher binding affinity to $\mathrm{CB}[6]$ than RA1. We also investigated whether a NIR laser $\left(1 \mathrm{~W} / \mathrm{cm}^{2}\right)$ could cross mouse tissues with different thickness (above the limit for UV radiation) and origins and trigger the release of RA1 from RA1-CB[6] @AuNR (Figure S4C). Our results show that up to $15 \%$ of RA1 was released being the extent dependent in the thickness and origin of the tissue. In a parallel set of experiments, we evaluated the binding affinity between RA1 and $\mathrm{CB}[6]$ at different temperatures (Additional file 1: Table S1). The release of $30 \%$ of RA1 from $\mathrm{CB}[6]$ @AuNRs required an increase of $15{ }^{\circ} \mathrm{C}$ in temperature. This temperature was higher than the one observed after laser irradiation $\left(\approx 10{ }^{\circ} \mathrm{C}\right)$ for the same level of RA1 release (i.e. $30 \%$ ), which suggested that the temperature reached at the surface of the AuNRs was higher than the bulk temperature, as observed in a study reported recently by us [11].

Overall, we have prepared a nanoformulation that releases RAn after activation by NIR while maintaining its stability in suspension. The displacement of the guest from the host is induced by the heating of the nanocarrier caused by its NIR activation. For the subsequent studies, we have used RA1 and RA2 since RA3 had relatively low activity.

\section{Cellular uptake and intracellular trafficking}

Next, we evaluated the interaction of our formulation with human cells. Recently, we have shown that formulations able to release intracellularly small molecules may modulate the differentiation of leukemic cells and reduce the progression of blood cancers [26]. Therefore, we first evaluated the cytotoxic profile of RA1-CB[6] @AuNRs (we used RA1 for proof of concept) against human leukemia cells, i.e., human bone marrow APL NB4 cells, using an ATP assay. The results showed that RA1-CB[6] @AuNRs had no substantial effect on leukemia cells for concentrations up to $50 \mu \mathrm{g} / \mathrm{mL}$ (Additional file 1: Figure S5A). We also evaluated the cytotoxic effect of NIR light in the cells. The cells where incubated for $4 \mathrm{~h}$ with RA1$\mathrm{CB}[6] @ A u N R s(50 \mu \mathrm{g} / \mathrm{mL})$, washed to remove the noninternalized AuNRs, and then irradiated during different times with NIR light at $2 \mathrm{~W} / \mathrm{cm}^{2}$ (Additional file 1: Figure S5B). The results showed low cytotoxic effect, below $20 \%$ with up to $2 \mathrm{~min}$ of irradiation and are in line with other reported studies $[11,49]$.

To investigate the uptake of RA1-CB[6] @AuNRs in NB4 cells, the intracellular distribution of the formulation was examined. RA1-CB[6] @AuNRs were chemically conjugated with tetramethylrhodamine (TRITC) thiol-PEG and incubated with NB4 cells for $4 \mathrm{~h}$. Then, the colocalization between RA1-CB[6] @AuNR-TRITC and early endosomes (immunostained for EEA1 epitope) was observed using confocal laser scanning microscopy (CLSM) (Fig. 4a). Most of the RA1-CB[6] @AuNR-TRITC escaped the early endosomes without light activation, 


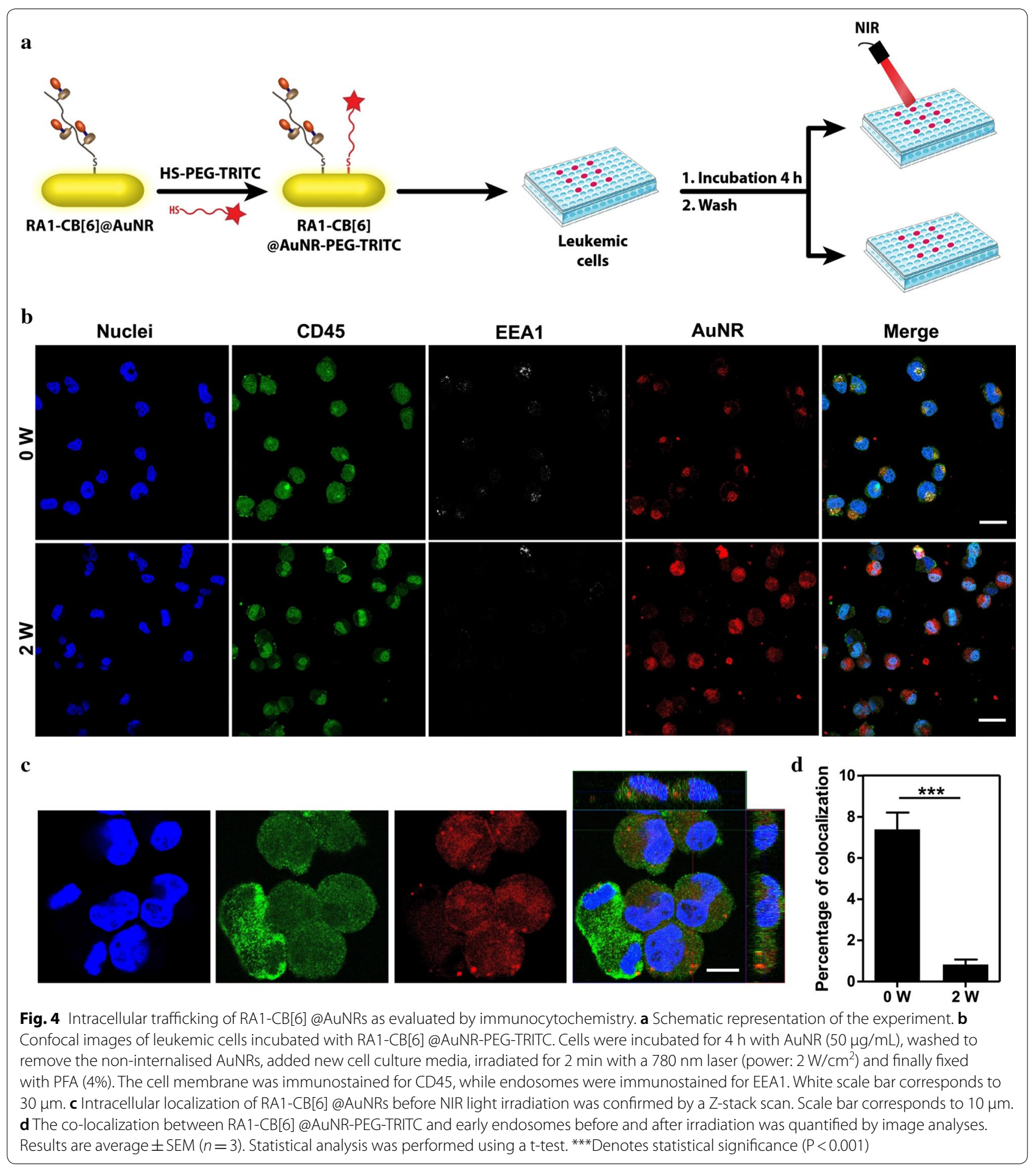

and were located in the cell cytoplasm (Fig. 4b-d). The exposure of the cells to NIR light increased the amount of AuNRs in the cell cytoplasm. The amount of RA1-CB[6] @AuNR per cell was determined by ICP-MS for different incubation times (Additional file 1: Figure S5C). The results showed a rapid internalization of the RA1-CB[6] $@ A u N R s$, since the internalization after $1 \mathrm{~h}$ of incubation was similar to the one obtained after $24 \mathrm{~h}$.

Taken together, the formulation RA1-CB[6] @AuNRs had no significant cytotoxic effect on leukemic cells for 
concentrations up to $50 \mu \mathrm{g} / \mathrm{mL}$ and was rapidly $(\approx 1 \mathrm{~h})$ internalized by the cells and accumulated in cell cytoplasm. Our results are aligned with previous studies showing that AuNRs were not cytotoxic against leukemic monocyte macrophages for concentrations up to $40 \mu \mathrm{g} /$ $\mathrm{mL}$ [50]. Interestingly, the uptake of AuNRs observed in NB4 cell line was higher $(\approx 7 \mathrm{pg} / \mathrm{cell})$ than the one previously observed in leukemic cells $(\approx 0.8 \mathrm{pg} /$ cell) [50] and this might be due to differences in AuNR surface composition and differences in cell types. In contrast to previous studies [51], our results indicate that RA1-CB[6] @ AuNRs escape the endolysosomal compartment. NB4 cells (acute myeloid subtype 3 , promyelocytic) express CD44, a transmembrane glycoprotein that is a receptor of HA [52]. It is possible that the interaction of HA with CD44 receptor potentiates AuNR cell uptake and endolysosomal escape, as it was observed recently with other AuNRs coated with HA [46]. This is an issue that deserves further investigation in the near future.

\section{Intracellular activation of RAn-CB[6] @AuNRs}

To investigate the biological impact of RAn-CB[6] @ AuNRs in leukemic reporter cells, we initially performed the release of RA conjugates outside the cells and then incubated the cells with the released contents (Fig. 5). With this in mind, RAn-CB[6] @AuNRs were either exposed or not to a NIR laser $\left(2 \mathrm{~W} / \mathrm{cm}^{2}\right)$ for $2 \mathrm{~min}$ after which the suspension was centrifuged and the following experimental groups were evaluated in the human bone marrow APL NB4 reporter cell line: (i) supernatant and resuspended pellet collected from RAn-CB[6] @AuNRs without NIR activation (Fig. 5a); (ii) supernatant and the resuspended pellet collected from RAn-CB[6] @AuNRs with NIR activation (Fig. 5c). In all cases, cells were incubated for $4 \mathrm{~h}$ with each solution/formulation, washed, cultured for additional $20 \mathrm{~h}$ and then the levels of luciferase quantified.

Our results showed that $\mathrm{CB}[6] @ A u N R s$ released a relatively small amount of RAn in the absence of NIR activation confirming the stability of the host-guest interaction (Fig. 5b). Moreover, the resuspended pellet showed low relative luciferase activity without NIR activation, while irradiation with NIR light the cells incubated for $4 \mathrm{~h}$ with the resuspended pellet lead to a high luciferase activity (Fig. 5b). On the other hand, CB[6] @AuNRs released a significant amount of RA1 or RA2 after NIR activation (Fig. 5d). Due to different binding affinities between RA1 or RA2 to CB[6] @AuNR, the supernatant RA1 showed higher luciferase activity relatively to the resuspended pellet, as compared to the supernatant with RA2.

Next, we monitored the biological impact of the intracellular release of RA1 from RA1-CB[6] @AuNRs in a leukemic cell line (Fig. 6a). RA1-CB[6] @AuNRs was selected for these tests in detriment of RA2-CB[6] @ AuNRs due to its high activity, based on the results obtained on the reporter cell line. The intracellular release of RA1 was followed by the expression of myeloid maturation marker $\mathrm{CD} 11 \mathrm{~b}^{+}$, a protein involved in the regulation of leukocyte adhesion and migration, using flow cytometry. Initially, we evaluated the impact of different concentrations of soluble RA1 in the differentiation of leukemic cells (Fig. 6b). Then, due to localized heating on AuNRs surface upon NIR irradiation, we studied the influence of irradiation time on RA1. The results showed that heating RA1 $(5 \mu \mathrm{M})$ for 5 min at different temperatures did not affect the percentage of cells expressing CD11b ${ }^{+}$(Fig. 6c).

To assess the release of RA1 from the CB[6] @AuNRs, leukemic cells were transfected for $4 \mathrm{~h}$, washed, activated or not by a NIR laser ( $\left.2 \mathrm{~min}, 2 \mathrm{~W} / \mathrm{cm}^{2}\right)$, cultured for additional $68 \mathrm{~h}$ and finally characterized by flow cytometry. Although non-irradiated cells also induced RA signaling, the results showed higher percentage of cells expressing $\mathrm{CD}_{11} \mathrm{~b}^{+}$upon NIR light activation (Fig. 6d). Moreover, when the cells were irradiated $24 \mathrm{~h}$ after the washing step (Fig. 6e), similar results were obtained, indicating the temporal control release of RA within cells.

Overall, our results demonstrated the controlled release of RA derivatives within leukemic cells after NIR activation. Although not investigated, the formulation proposed here may be suitable for the intracellular delivery of more than one ligand, being the controlled release governed by the binding affinity of each ligand to the host and the temperature profile controlled by the irradiation exposure (i.e. ligands with low affinity will require low temperature for release, while ligands with high affinity will require high temperatures). During the preparation of the current work, a study has explored host-guest chemistry to release small molecules from nanocarriers upon NIR light activation within cells [13], however, the spatio-temporal controlled release of the drug from the macrocycle upon NIR activation was not demonstrated. In the previous study, the CB [7] was adsorbed to the surface of gold nanostars and thus not chemically conjugated to the surface of the nanocarrier like in the current study. Although the authors were able to demonstrate the encapsulation of an anticancer drug, the system was very leaky since $30 \%$ of the drug was released without light activation. It is anticipated that the direct attachment of the macrocycle to the gold nanostars decreased the binding strength of the guest to the host. Moreover, the authors did not show whether the release from the gold nanoshell was the drug or the drug interacting with the macrocycle. Although the intracellular release of small molecules has been reported by other light-disassembled nanoformulations 


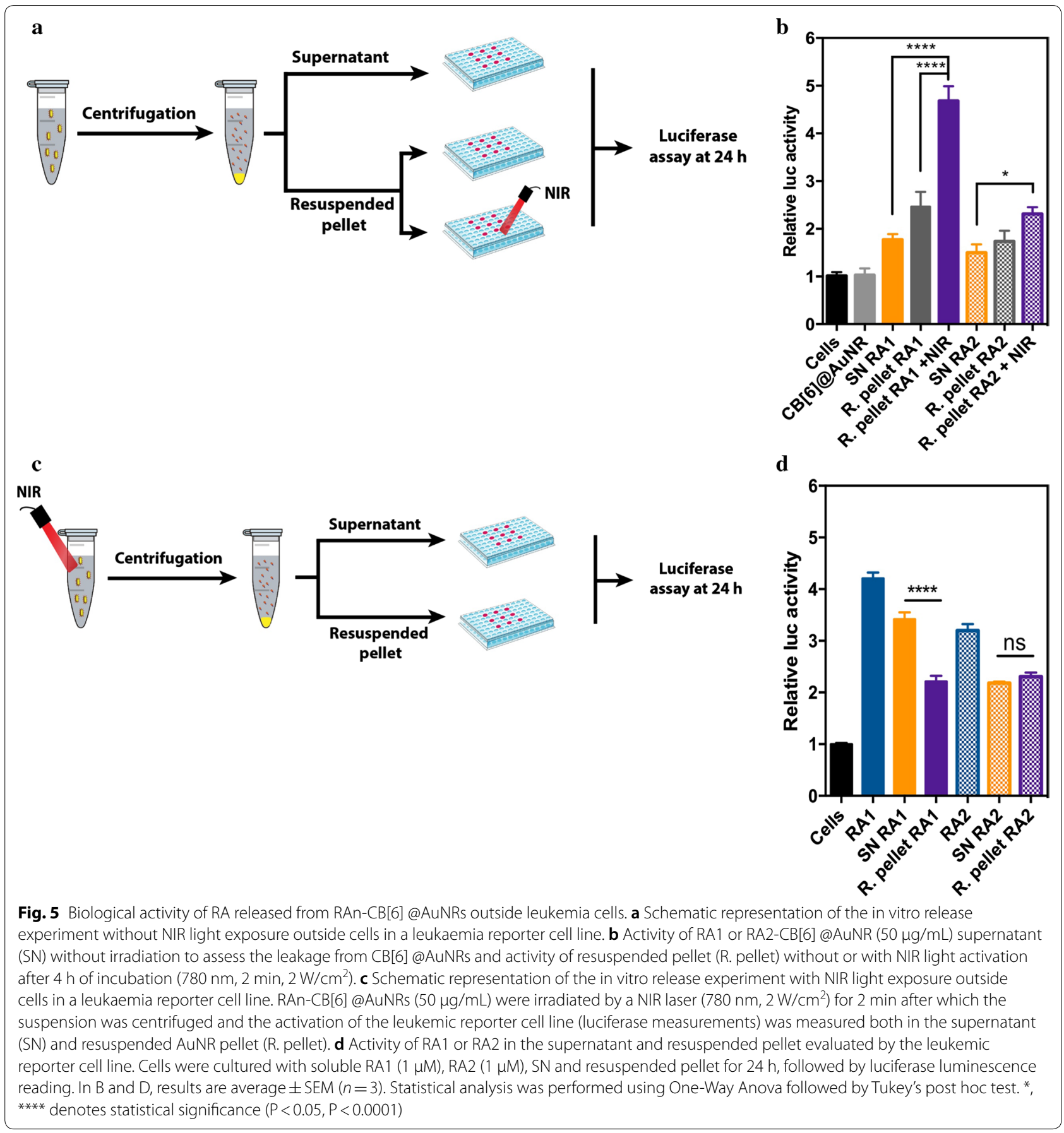

[12], light-induced thermal de-hybridization of oligonucleotides from nanocarriers [9], light-induced thermal dissociation of small molecules from a polycationic linker attached to a AuNR [53], or light induced cleavage of a linker attached to the nanocarrier and having in the other extremity a small molecule [54], the strategy adopted in this study is relatively simple for the design of light-activatable systems given that it does not require significant alterations in the chemistry of the molecule of interest. Overall, this platform allows the immobilization of multiple molecules, with different chemical structures, to one single nanocarrier and, importantly for clinical applications, the activation by NIR light will facilitate tissue penetration. 


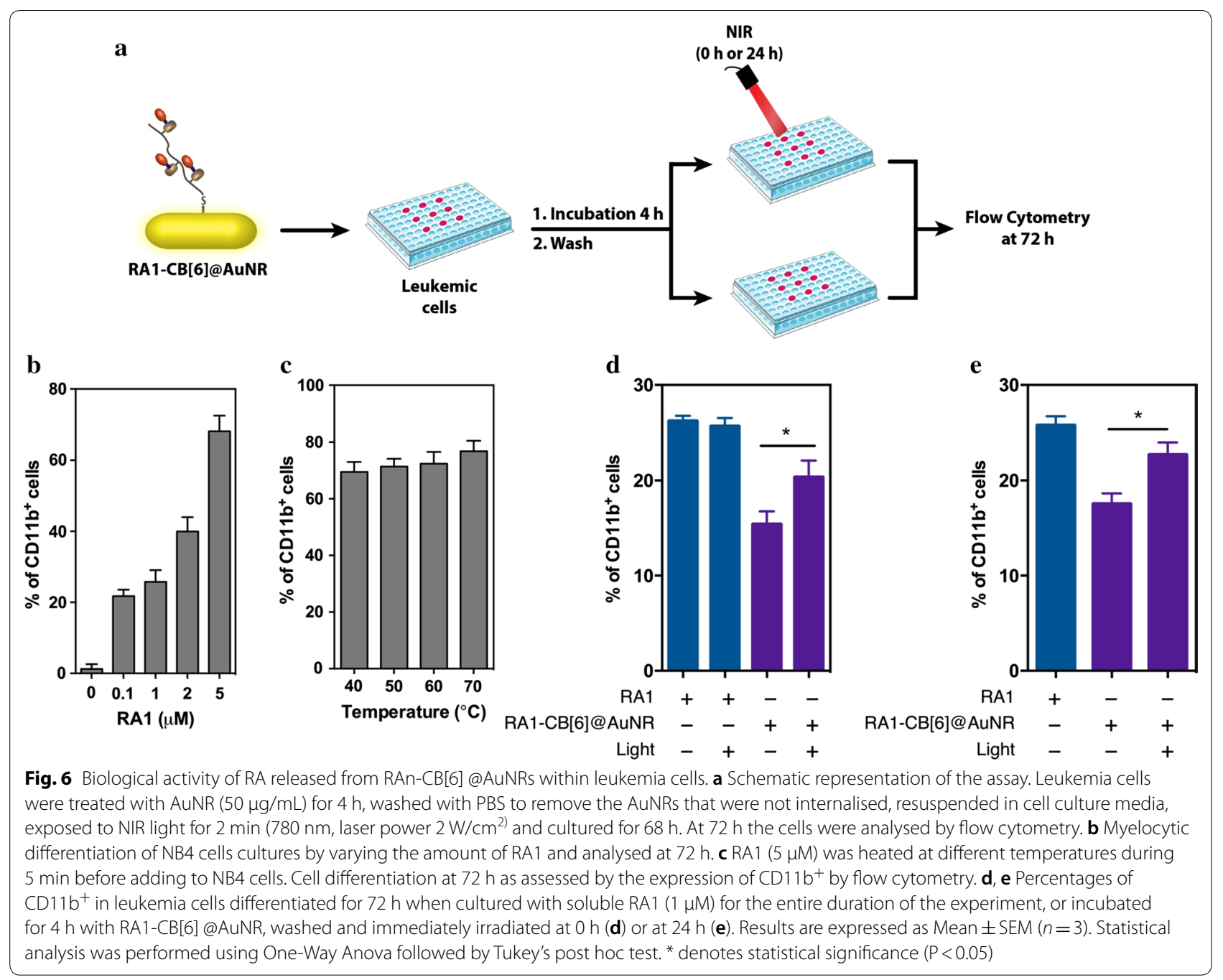

\section{Conclusions}

Here we report a formulation that integrates a NIR laser sensitive core and a polymeric coating composed by a macrocycle $\mathrm{CB}[6]$ for host-guest chemistry. This formulation may complex any small molecule conjugated with a guest ligand having affinity for the macrocycle. We demonstrated this concept with RA, which is a small molecule commonly used for therapeutic and regenerative medicine approaches. We showed that RA conjugated with different $\mathrm{CB}[6]$ ligands had different affinity to the formulation and, depending on the ligand chemistry, up to $65 \mu \mathrm{g}$ of RA was immobilized per mg of AuNRs. Importantly, upon exposure to NIR laser the formulation was able to release approximately $30 \%$ of RA within 2 min. We demonstrated the biological effect of RA derivatives released intracellularly in a reporter cell line and on the expression of $\mathrm{CD} 11 \mathrm{~b}$ protein at the cell surface. We envision that this formulation might open new opportunities to tackle leukemic niches as recently demonstrated by us using a UV-light activatable formulation, which has a much lower tissue penetration [26].

\section{Supplementary information}

Supplementary information accompanies this paper at https://doi. org/10.1186/s12951-019-0530-y.

Additional file 1. Data relative to the characterization of RA and AuNRs conjugates, cytotoxicity, AuNRs heating profile, internalization and binding affinities of RAn to AuNRs.

\section{Acknowledgements}

The authors wish to thank Dr. Hugo Fernandes (Faculty of Medicine, University of Coimbra) for his helpful suggestions and corrections.

\section{Authors' contributions}

Conception and design: VF, LF, Development of methodology: VF, ML, LF. Writing and revision of the manuscript: VF, ML, LF. Acquisition of data: VF, ML. All authors read and approved the final manuscript. 


\section{Funding}

The authors would like to thank the financial support of ERA Chair project (ERA@UC, Ref: 669088) through EU Horizon 2020 program, the POCI-01-0145FEDER-016390 (acronym: CANCEL STEM) and POCI-01-0145-FEDER-029414 (acronym: LIghtBRARY) projects through Compete 2020 and FCT programs, and FCT (Portugal, SFRH/BPD/102103/2014) for supporting this work and the critical input of Dr. Hugo Fernandes (Faculty of Medicine, University of Coimbra). NMR data was collected at the UC-NMR facility which is supported in part by FEDER - European Regional Development Fund through the COMPETE Programme (Operational Programme for Competitiveness) and by National Funds through FCT_Fundação para a Ciência e a Tecnologia (Portuguese Foundation for Science and Technology) through grants REEQ/481/QUI/2006, RECI/QEQ-QFI/0168/2012, CENTRO-07-CT62-FEDER-002012, and Rede Nacional de Ressonância Magnética Nuclear (RNRMN).

\section{Availability of data and materials}

All data generated or analyzed during this study are included in this published article and its additional information files.

\section{Ethics approval and consent to participate}

Not applicable.

\section{Consent for publication}

All authors agreed to submit this study.

\section{Competing interests}

The authors declare that they have no competing interests.

\section{Author details}

${ }^{1}$ CNC-Center for Neurosciences and Cell Biology, University of Coimbra, 3004-517 Coimbra, Portugal. ${ }^{2}$ Faculty of Medicine, University of Coimbra, 3000-548 Coimbra, Portugal.

Received: 10 July 2019 Accepted: 10 September 2019

Published online: 16 September 2019

\section{References}

1. Leader B, Baca QJ, Golan DE. Protein therapeutics: a summary and pharmacological classification. Nat Rev Drug Discov. 2008;7:21-39.

2. Gu Z, Biswas A, Zhao M, Tang Y. Tailoring nanocarriers for intracellular protein delivery. Chem Soc Rev. 2011;40:3638-55.

3. Chou LY, Ming K, Chan WC. Strategies for the intracellular delivery of nanoparticles. Chem Soc Rev. 2011;40:233-45.

4. Yameen B, Choi WI, Vilos C, Swami A, Shi J, Farokhzad OC. Insight into nanoparticle cellular uptake and intracellular targeting. J Control Release. 2014;190:485-99.

5. Blanco E, Shen H, Ferrari M. Principles of nanoparticle design for overcoming biological barriers to drug delivery. Nat Biotechnol. 2015;33:941-51.

6. Farokhzad OC, Langer R. Impact of nanotechnology on drug delivery. ACS Nano. 2009;3:16-20.

7. Allen TM, Cullis PR. Liposomal drug delivery systems: from concept to clinical applications. Adv Drug Deliv Rev. 2013;65:36-48.

8. Couvreur P. Drug delivery: replenishing reservoirs in vivo. Nat Nanotechnol. 2014;9:874-5.

9. Lino MM, Simoes S, Vilaca A, Antunes H, Zonari A, Ferreira L. Modulation of angiogenic activity by light-activatable miRNA-loaded nanocarriers. ACS Nano. 2018;12(6):5207-20.

10. Wang YF, Kohane DS. External triggering and triggered targeting strategies for drug delivery. Nat Rev Mater. 2017;2:17020.

11. Lino MM, Simoes S, Pinho S, Ferreira L. Intracellular delivery of more than one protein with spatio-temporal control. Nanoscale. 2017;9:18668-80.

12. Jimenez-Balsa A, Pinto S, Quartin E, Lino MM, Francisco V, Ferreira L. Nanoparticles conjugated with photocleavable linkers for the intracellular delivery of biomolecules. Bioconjug Chem. 2018;29:1485-9.

13. Xu P, Feng Q, Yang X, Liu S, Xu C, Huang L, Chen M, Liang F, Cheng Y. Near infrared light triggered cucurbit[7]uril-stabilized gold nanostars as a supramolecular nanoplatform for combination treatment of cancer. Bioconjug Chem. 2018;29:2855-66.
14. Kim K, Selvapalam N, Ko YH, Park KM, Kim D, Kim J. Functionalized cucurbiturils and their applications. Chem Soc Rev. 2007;36:267-79.

15. Lagona J, Mukhopadhyay P, Chakrabarti S, Isaacs L. The cucurbit[n] uril family. Angew Chem Int Ed Engl. 2005;44:4844-70.

16. Barrow SJ, Kasera S, Rowland MJ, del Barrio J, Scherman OA. Cucurbiturilbased molecular recognition. Chem Rev. 2015;115:12320-406.

17. Li H, Tan L-L, Jia P, Li Q-L, Sun Y-L, Zhang J, Ning Y-Q, Yu J, Yang Y-W. Near-infrared light-responsive supramolecular nanovalve based on mesoporous silica-coated gold nanorods. Chem Sci. 2014;5:2804

18. Marquez DT, Scaiano JC. Visible and near-infrared plasmon-mediated molecular release from cucurbit[6]uril mesoporous gated systems. Langmuir. 2016;32:13764-70.

19. Ghosh P, Han G, De M, Kim CK, Rotello VM. Gold nanoparticles in delivery applications. Adv Drug Deliv Rev. 2008;60:1307-15.

20. Mieszawska AJ, Mulder WJ, Fayad ZA, Cormode DP. Multifunctional gold nanoparticles for diagnosis and therapy of disease. Mol Pharm. 2013;10:831-47.

21. Cherukuri P, Glazer ES, Curley SA. Targeted hyperthermia using metal nanoparticles. Adv Drug Deliv Rev. 2010;62:339-45.

22. Giljohann DA, Seferos DS, Daniel WL, Massich MD, Patel PC, Mirkin CA. Gold nanoparticles for biology and medicine. Angew Chem Int Ed Engl. 2010;49:3280-94.

23. Huang X, Jain PK, El-Sayed IH, El-Sayed MA. Plasmonic photothermal therapy (PPTT) using gold nanoparticles. Lasers Med Sci. 2008;23:217-28.

24. Maia J, Santos T, Aday S, Agasse F, Cortes L, Malva JO, Bernardino L, Ferreira L. Controlling the neuronal differentiation of stem cells by the intracellular delivery of retinoic acid-loaded nanoparticles. ACS Nano. 2011;5:97-106.

25. Santos T, Ferreira R, Maia J, Agasse F, Xapelli S, Cortes L, Braganca J, Malva JO, Ferreira L, Bernardino L. Polymeric nanoparticles to control the differentiation of neural stem cells in the subventricular zone of the brain. ACS Nano. 2012;6:10463-74.

26. Boto C, Quartin E, Cai Y, Martin-Lorenzo A, Cenador MBG, Pinto S, Gupta R, Enver T, Sanchez-Garcia I, Hong D, et al. Prolonged intracellular accumulation of light-inducible nanoparticles in leukemia cells allows their remote activation. Nat Commun. 2017:8:15204.

27. Ferreira R, Fonseca MC, Santos T, Sargento-Freitas J, Tjeng R, Paiva F, Castelo-Branco M, Ferreira LS, Bernardino L. Retinoic acid-loaded polymeric nanoparticles enhance vascular regulation of neural stem cell survival and differentiation after ischaemia. Nanoscale. 2016;8:8126-37.

28. Bouriez D, Giraud J, Gronnier C, Varon C. Efficiency of All-Trans Retinoic Acid on Gastric Cancer: A Narrative Literature Review. Int J Mol Sci. 2018;19(11):3388

29. Arrieta O, Hernandez-Pedro N, Fernandez-Gonzalez-Aragon MC, Saavedra-Perez D, Campos-Parra AD, Rios-Trejo MA, Ceron-Lizarraga T, Martinez-Barrera L, Pineda B, Ordonez G, et al. Retinoic acid reduces chemotherapy-induced neuropathy in an animal model and patients with lung cancer. Neurology. 2011;77:987-95.

30. Donato LJ, Suh JH, Noy N. Suppression of mammary carcinoma cell growth by retinoic acid: the cell cycle control gene Btg2 is a direct target for retinoic acid receptor signaling. Cancer Res. 2007:67:609-15.

31. Kelsey L, Katoch P, Johnson KE, Batra SK, Mehta PP. Retinoids regulate the formation and degradation of gap junctions in androgen-responsive human prostate cancer cells. PLoS ONE. 2012;7:e32846.

32. Warrell RP Jr, Frankel SR, Miller WH Jr, Scheinberg DA, Itri LM, Hittelman WN, Vyas R, Andreeff M, Tafuri A, Jakubowski A, et al. Differentiation therapy of acute promyelocytic leukemia with tretinoin (all-trans-retinoic acid). N Engl J Med. 1991;324:1385-93.

33. Hadjipavlou-Litina D, Magoulas GE, Bariamis SE, Drainas D, Avgoustakis K, Papaioannou D. Does conjugation of antioxidants improve their antioxidative/anti-inflammatory potential? Bioorg Med Chem. 2010;18:8204-17.

34. Papaioannou D, Militsopoulou M, Bariamis S, Athanassopoulos C. Synthetic studies towards the development of psoralen-acidic retinoid conjugates and hybrids. Synthesis. 2008;2008:3433-42.

35. Magoulas G, Papaioannou D, Papadimou E, Drainas D. Preparation of spermine conjugates with acidic retinoids with potent ribonuclease $P$ inhibitory activity. Eur J Med Chem. 2009;44:2689-95.

36. Shu XZ, Liu Y, Luo Y, Roberts MC, Prestwich GD. Disulfide cross-linked hyaluronan hydrogels. Biomacromol. 2002;3:1304-11. 
37. Nikoobakht B, El-Sayed MA. Preparation and growth mechanism of gold nanorods (NRs) using seed-mediated growth method. Chem Mater. 2003;15:1957-62.

38. Nolting B, Yu JJ, Liu G-Y, Cho S-J, Kauzlarich S, Gervay-Hague J. Synthesis of gold glyconanoparticles and biological evaluation of recombinant Gp120 Interactions. Langmuir. 2003;19:6465-73.

39. Kuo JW. Practical aspects of hyaluronan based medical products. Boca Raton: CRC/Taylor \& Francis; 2006.

40. Toole BP. Hyaluronan: from extracellular glue to pericellular cue. Nat Rev Cancer. 2004:4:528-39.

41. Jung H, Park KM, Yang JA, Oh EJ, Lee DW, Park K, Ryu SH, Hahn SK, Kim K. Theranostic systems assembled in situ on demand by host-guest chemistry. Biomaterials. 2011;32:7687-94.

42. Jones ST, Taylor RW, Esteban R, Abo-Hamed EK, Bomans PH, Sommerdijk NA, Aizpurua J, Baumberg JJ, Scherman OA. Gold nanorods with subnanometer separation using cucurbit[n] uril for SERS applications. Small. 2014;10:4298-303.

43. Han Y, Yang X, Liu Y, Ai Q, Liu S, Sun C, Liang F. Supramolecular controlled cargo release via near infrared tunable cucurbit[7]uril-gold nanostars. Sci Rep. 2016;6:22239.

44. Xia X, Yang M, Wang Y, Zheng Y, Li Q, Chen J, Xia Y. Quantifying the coverage density of poly(ethylene glycol) chains on the surface of gold nanostructures. ACS Nano. 2012;6:512-22.

45. Liu H, Pierre-Pierre N, Huo Q. Dynamic light scattering for gold nanorod size characterization and study of nanorod-protein interactions. Gold Bulletin. 2012;45:187-95.

46. Xu W, Qian J, Hou G, Suo A, Wang Y, Wang J, Sun T, Yang M, Wan X, Yao Y. Hyaluronic acid-functionalized gold nanorods with $\mathrm{pH} / \mathrm{NIR}$ dual-responsive drug release for synergetic targeted photothermal chemotherapy of breast cancer. ACS Appl Mater Interfaces. 2017;9:36533-47.
47. Feng Y, Xue S-F, Fan Z-F, Zhang Y-Q, Zhu Q-J, Tao Z. Host-guest complexes of some cucurbit[n]urils with the hydrochloride salts of some imidazole derivatives. J Incl Phenom Macrocycl Chem. 2009;64:121-31.

48. Kim Y, Kim H, Ko YH, Selvapalam N, Rekharsky MV, Inoue Y, Kim K. Complexation of aliphatic ammonium ions with a water-soluble cucurbit[6]uril derivative in pure water: isothermal calorimetric, NMR, and X-ray crystallographic study. Chemistry. 2009:15:6143-51.

49. Wang $L$, Jiang $X$, Ji Y, Bai R, Zhao Y, Wu X, Chen C. Surface chemistry of gold nanorods: origin of cell membrane damage and cytotoxicity. Nanoscale. 2013;5:8384-91.

50. Xie X, Liao J, Shao X, Li Q, Lin Y. The effect of shape on cellular uptake of gold nanoparticles in the forms of stars, rods, and triangles. Sci Rep. 2017;7:3827.

51. Zhang W, Ji Y, Wu X, Xu H. Trafficking of gold nanorods in breast cancer cells: uptake, lysosome maturation, and elimination. ACS Appl Mater Interfaces. 2013;5:9856-65.

52. Gadhoum Z, Leibovitch MP, Qi J, Dumenil D, Durand L, Leibovitch S, Smadja-Joffe F. CD44: a new means to inhibit acute myeloid leukemia cell proliferation via p27Kip1. Blood. 2004;103:1059-68.

53. Huschka R, Barhoumi A, Liu Q, Roth JA, Ji L, Halas NJ. Gene silencing by gold nanoshell-mediated delivery and laser-triggered release of antisense oligonucleotide and siRNA. ACS Nano. 2012;6:7681-91.

54. Yang Y, Liu F, Liu X, Xing B. NIR light controlled photorelease of siRNA and its targeted intracellular delivery based on upconversion nanoparticles. Nanoscale. 2013:5:231-8.

\section{Publisher's Note}

Springer Nature remains neutral with regard to jurisdictional claims in published maps and institutional affiliations.
Ready to submit your research? Choose BMC and benefit from:

- fast, convenient online submission

- thorough peer review by experienced researchers in your field

- rapid publication on acceptance

- support for research data, including large and complex data types

- gold Open Access which fosters wider collaboration and increased citations

- maximum visibility for your research: over $100 \mathrm{M}$ website views per year

At BMC, research is always in progress.

Learn more biomedcentral.com/submissions 